\title{
Science and Politics
}

SALOMON, J.-J. (MacMillan, London, 1973) 267 pages + Index. £5.50. (Original French edition: Editions du Seuil, 1970).

The relationships between science and politics are elusive; it requires courage to even attempt to establish them. However, with a broad, bold sweep which takes in rival philosophers, prominent politicians and eminent scientists, Jean-Jacques Salo. mon sets out the case that science and politics are now inextricably interwined. With hindsight of some three years since the original French version was written, it is apparent that new relationships are emerging and, by projection, farther different interactions between science and politics would seem likely in future. In other words, Science and Politics should not be considered a definitive text, but rather as a signpost en route to further assessment.

Salomon is head of the Science Policy Division of the Organisation for Economic Cooperation and Development, and his emphasis on the concurrence of interests of science and society might be expected as, for example, when he writes:

"The scientific society is not only the society which wills science as one of its ends, but also the society in which scientists desire their own ends to coincide with those of society."

That statement may be true, occasionally, when both a scientific society and society-at-large are explicit in defining their ends. However, in many dominant areas of modern life, either a scientific society has not adopted ends, or else society-at-large com- prises rival groups with competing, and often conflicting, ends. In general, a scientific society concerns itself only with promotion of efficient professional communications, and, at most, with education and professional status in addition. Even with these limited ends, a scientific society may well find itself in conflict with societyat-large !

In dealing with the myths of science policy (planning and forecasting, and allocation of resources), Salomon has scathing remarks to address to these who confuse the rationality of science itself with the procedures for establishing science policy. Particularly under attack, perhaps because it has gained some ground, comes technological forecasting. Salomon indicates that success for technological forecasting is possible only when the forecaster creates and arranges the events he foretells.

It is fascinating to read of the contempt that politicians have displayed for the most eminent physicists when the latter attempted to interfere with crucial, political judgments concerning, for example, atomic weapons. Here, there appears to be mutual incomprehension between physicists, who view political judgments as extensions of their scientific contributions, and the politicians, who look upon scientific contributions as no different from those of management, engineers, lawyers, economists, etc. As President of the United States, Truman is reported to have said after a visit of J.R. Oppenheimer, scientific director of the Manhattan Project which developed the atomic bomb: "Don't ever bring that damn fool in here again. He didn't set that bomb off. I did. That kind of snivelling makes me sick." That dismissal certainly sums up one of the pitfalls of responsibility that a scientist is in danger of confronting.

Salomon's description of the ambivalence of the 'neutralist' pretensions of scientific thought are vivid when he deals with the field of international scientific cooperation. He reveals that in all international scientific relations, cooperation must be looked at from two angles - scientific interest and political expediency. One conclusion he draws is stark -

“...all joint undertakings will be the subject of intergovernmental agreements, they will originate and develop in a political context, and they will be obedient to political motives as well as to scientific considerations."

In the final paragraphs of Science and Politics, Salomon introduces distinctions between 'savants' and scientists: the scientist expresses a professional reality, the savant an ideological imperative; the scientist is a production agent, the savant a culture figure. Whether these distinctions are valid remains to be seen, but, according to Salomon, the future of science in relation to politics depends on the continuous emergence of individual savants from the mass of scientists. However, it is difficult to see what incentive there will be for those future savants in a world so dominated by the political order as Salomon foresees.

Salomon's Science and Politics is, without doubt, a stimulating book which deserves the attention of any European physicist who can obtain a copy.

\section{Regional Science and Technology Policy}

\section{An attempt at an International Biblio- graphy}

S. Dedijer (Lund) and U. Tonim (Belgrade) have available what they call 'an attempt' at an international regional science and technology bibliography. The compilers justified the effort by claiming that regional orientation is the latest phase in development of the social innovation, science and technology policy. They traced four stages since 1945 :

a. 1945-55 - the 'laissez inventer et innover' stage - when the private and public 'market' for inventions, discoveries and innovations determined what research, development and innovation work was done.

b. $1955-68$ - the aggregate stage when individual countries developed specific policies for defence, atomic energy, space, industry, etc., with very feeble attempts to coordinate or to integrate them.

c. Starting in the fifties, many countries attempted to coordinate the aggregate of such specific policies by creating the appropriate structures for that purpose close to or at the centres of political power. d. Now, science and technology policies are being approached from the point of view of their integral growth with growth of the social system, not only as its needs are now perceived, but also with eyes to future, long-term needs.

The bibliography, which could be better, as the compilers readily admit, with a larger investment of time, money and other resources, may be obtained from S. Dedijer, Research Policy Program, University of Lund, Sölvegatan 8, Lund, Sweden. 